\title{
Epidemiology, Outcomes and Coronary Angiography Findings of Patients Following Out-of-Hospital Cardiac Arrest A single-centre experience from Oman
}

"Sunil K. Nadar, Mohammed Mujtaba, Hafidh Al-Hadi, Muhammed Sadiq, Adil Al-Riyami, Mehar Ali, Hatim Al-Lawati

$$
\begin{aligned}
& \text { معدل انتشار وحصصلات ونتائج تصوير الشرايين ما بعد } \\
& \text { السكتة القلبية خارج المستشفى } \\
& \text { تحربة مركز واحد في عمان }
\end{aligned}
$$

$$
\text { سونيل ندار، محمد بحتبى، حفيظ الهادي، محمد أطهر صادق، عادل الريامي، ميهار علي، حاتم اللواتي }
$$

ABSTRACT: Objectives: Out-of-hospital cardiac arrests (OHCAs) are a leading cause of death worldwide. However, data regarding the management and outcomes of affected patients are lacking in the Middle East. The current study aimed to present the angiographic findings and outcomes of patients presenting with OHCA in Muscat, Oman. Methods: This retrospective study took place between January 2012 and December 2016 at the Sultan Qaboos University Hospital (SQUH), Muscat, Oman. All adult patients who presented following an OHCA to the Emergency Department of SQUH during the study period were included. Demographic and clinical data were collected from electronic medical records. Results: A total of 216 patients were included in the study. The majority (63.9\%) presented after having collapsed, while $22.3 \%$ presented with chest pains. Asystole was the most frequent initial cardiac rhythm (62.5\%), with only $10 \%$ having ventricular tachycardia/fibrillation. Very few patients (1.4\%) had received cardiopulmonary resuscitation (CPR) prior to presentation. In total, 85 patients (39.4\%) returned to spontaneous circulation (RSC); of these, post-RSC electrocardiography revealed an ST-segment elevation in $41.2 \%$ and normal findings in $23.5 \%$. There were 63 patients who underwent coronary angiography, with 28 requiring stenting. Overall, 13\% of patients survived and were discharged, although three survivors suffered permanent hypoxic brain damage. Conclusion: The overall survival rate of patients who had experienced an OHCA was low. Education programmes should focus on the benefits of immediate CPR for individuals experiencing an OHCA, with more opportunities for CPR training to be made available to the general public in Oman.

Keywords: Out-of-Hospital Cardiac Arrest; Cardiopulmonary Resuscitation; Patient Outcome Assessment; Survival Rate; Coronary Angiography; Oman.

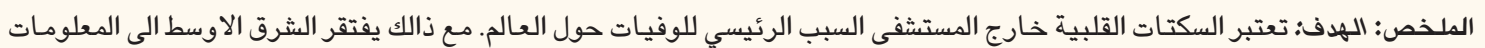

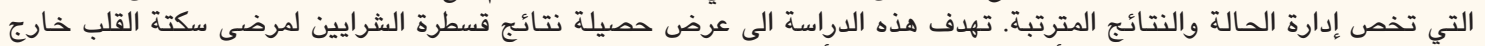

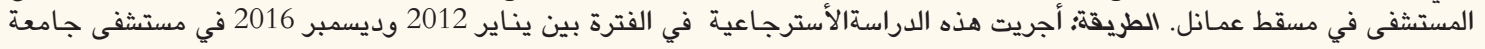

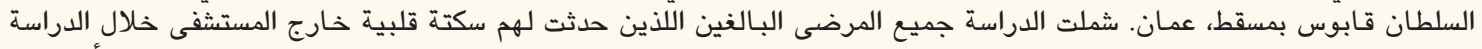

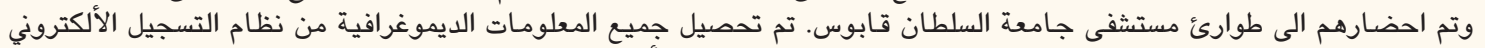

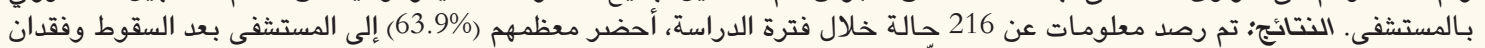

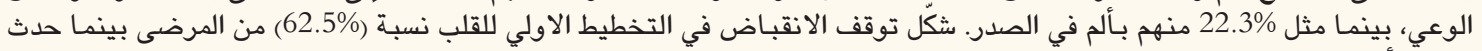

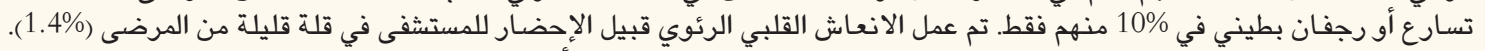

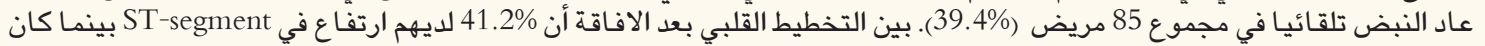

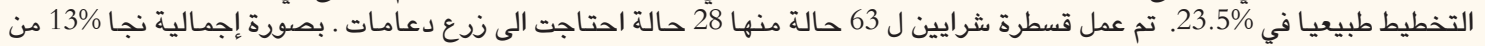

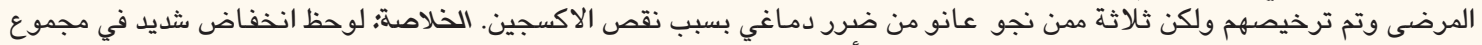

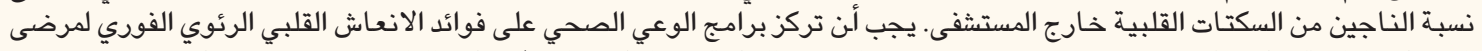

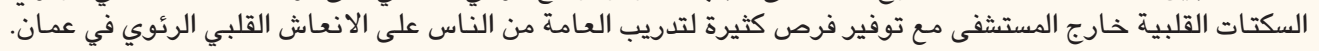

الكلمات المفتاحية؛ السكتات القلبية خارج المستثفى؛ الانعاش القلبي الرئوي؛ تقييم ما يؤول اليه المريض؛ معدل النجاة؛ قسطرة القلب؛ عمان.

\section{Advances in KNowledge}

To the best of the authors' knowledge, this study is the first to investigate the outcomes of patients following an out-of-hospital cardiac arrest (OHCA) in Oman. 
Despite early intervention, patients were found to have a poor survival rate following an OHCA. Moreover, a low rate of bystander cardiopulmonary resuscitation (CPR) was observed.

Application to Patient Care

The findings of the current study indicate that the Omani public should be educated about the importance of bystander CPR and early medical attention in $O H C A$ cases.

$\mathrm{O}$ UT-OF-HOSPITAL CARDIAC ARREST (OHCA) carries a very poor prognosis and is a leading cause of death worldwide. ${ }^{1,2}$ The annual incidence is between 36-81 events per 100,000 individuals, with most cases occurring at home and only $20 \%$ occurring in public places..$^{3-5}$ Survival rates vary from less than 10\% in England and Scotland to over $20 \%$ in Holland and Norway. ${ }^{2,67}$ Many factors have been identified as contributing to the survival of OHCA patients, with the early initiation of first aid or cardiopulmonary resuscitation (CPR) being one of the most important. ${ }^{8}$ This form of prehospital management, known as the "chain of survival", has become increasingly popular in Western countries.

Previous research shows that more than $70 \%$ of patients who are resuscitated following an OHCA have significant coronary artery disease, although this might not always be the cause of the cardiac arrest. ${ }^{10}$ Current guidelines and consensus statements recommend that immediate coronary angiography be performed for resuscitated OHCA patients in whom post-resuscitation electrocardiography (ECG) shows an ST-segment elevation, while early coronary angiography is indicated for patients with unexplained OHCA without an ST-segment elevation. . $^{11,12}$

Unfortunately, very little research is available concerning the incidence of OHCA and the outcomes of affected patients in Middle Eastern countries such as Oman. In 2017, the population of Muscat, the capital city of Oman, was reported to be approximately $1,475,000 .{ }^{13}$ Based on this, the annual incidence of OHCA in the Omani population is estimated to be between 516-780 cases per year., ${ }^{4,5}$ The current study aimed to describe the epidemiological patterns of patients presenting to a tertiary care centre in Oman following an OHCA event. In addition, the survival rate and demographic and angiographic features of resuscitated OHCA patients were assessed.

\section{Methods}

This retrospective study was conducted at the Sultan Qaboos University Hospital (SQUH), Muscat, Oman, between January 2012 and December 2016 and included all adult patients presenting during this period to the Emergency Department of SQUH following an OHCA. Only individuals over 18 years old who had experienced a cardiac arrest requiring CPR at home, in the community or en route to the hospital (i.e. either in an ambulance or another vehicle) were included in the study. Patients for whom there was a clear cause for cardiac arrest (e.g. drowning, a drug overdose or motor vehicle crash) and those with a chronic terminal illness (i.e. cancer or a debilitating stroke) were excluded. In addition, patients who were declared dead on arrival (DOA) were not included in the analysis, as emergency department physicians would have deemed such patients irresuscitable due to their physical condition or delay in presentation.

Eligible patients were identified from the SQUH Emergency Department log book and pertinent data collected from the patients' electronic medical records. In all OHCA cases, an early invasive strategy was initiated as per the recommendations of international guidelines, in which resuscitated OHCA patients with no obvious cause for the cardiac arrest were scheduled for an immediate or early coronary angiography, depending on their ECG results. ${ }^{11,12}$ Subsequently, the identification of a 'culprit' lesion or vessel requiring stenting was determined by either the presence of total occlusion or a tight stenosis with a hazy appearance and/or flow of thrombolysis in cases with type 2 myocardial infarctions.

Statistical analyses were performed using the Statistical Package for the Social Science (SPSS), Version 21.0 (IBM Corp., Armonk, New York, USA). A $P$ value of $<0.05$ was considered statistically significant. All categorical variables were described as frequencies and percentages. Means and standard deviations were used to present continuous normally-distributed variables, while variables which were not normally distributed were presented as medians and interquartile ranges. A Chi-squared test was used to compare categorical variables and a Student's t-test was used to compare mean age. Ethical approval for this study was obtained from the Medical Research \& Ethics Committee of the College of Medicine \& Health Sciences at Sultan Qaboos University (MREC \#1156).

\section{Results}

A total of 216 adult patients presented to SQUH following an OHCA during the study period. Of these, $150(69.4 \%)$ were male and $66(30.6 \%)$ were 
Table 1: Demographic and clinical characteristics of patients presenting following an out-of-hospital cardiac arrest to the Sultan Qaboos University Hospital, Muscat, Oman $(\mathrm{N}=216)$

\begin{tabular}{lc} 
Characteristic & $\mathbf{n}(\%)$ \\
Mean age in years & $55 \pm 17$ \\
Gender & \\
Male & $150(69.4)$ \\
Female & $66(30.6)$ \\
Method of arrival & \\
Private car & $213(98.6)$ \\
EMS & $3(1.4)$ \\
Risk factors* & \\
Diabetes & $73(33.8)$ \\
HTN & $87(40.3)$ \\
History of IHD & $28(13)$ \\
Unknown & $67(31)$ \\
Presentation & $23(10.6)$ \\
Collapsed & $2(0.9)$ \\
Chest pain & $137(63.7)$ \\
Breathlessness & $49(22.7)$ \\
Initial cardiac rhythm & $30(14)$ \\
Asystole & \\
PEA & $54(63)$ \\
VT/VF & \\
Heart blockage & \\
Patient outcome & \\
Died & \\
\hline Survived & \\
\hline
\end{tabular}

EMS = emergency medical services; HTN = hypertension; $I H D=$ ischae mic heart disease; $P E A=$ pulseless electrical activity; $V T / V F=$ ventricular tachycardia/fibrillation

*Percentages do not add up to $100 \%$ as some patients may have had several risk factors.

female. The mean age was $55 \pm 17$ years old. The vast majority of patients (98.6\%) were brought to the hospital by a relative or friend, with only three patients (1.4\%) transferred by the emergency medical services (EMS). Most patients (63.7\%) had collapsed, while the remaining patients presented with chest pain $(22.3 \%)$ or breathlessness (14\%). The initial cardiac rhythm for most patients was asystole (63.4\%), while 54 (25\%) had pulseless electrical activity, 23 (10.6\%) had ventricular tachycardia/fibrillation (VT/VF) and two patients (0.9\%) had a heart blockage. The overall survival rate was $13 \%$ [Table 1]. Of the 28 surviving patients, three had permanent hypoxic brain injuries and were
Table 2: Angiographic findings of resuscitated" patients presenting following an out-of-hospital cardiac arrest to the Sultan Qaboos University Hospital, Muscat, Oman $(\mathrm{N}=85)$

\begin{tabular}{|c|c|c|c|}
\hline \multirow[t]{2}{*}{ ECG findings } & \multicolumn{3}{|c|}{ n (\%) } \\
\hline & Total & $\begin{array}{c}\text { Significant } \\
\text { disease } \\
(n=42)\end{array}$ & $\begin{array}{l}\text { Stented } \\
(\mathrm{n}=28)\end{array}$ \\
\hline Normal & 25 (29.4) & 7 (16.7) & 5 (17.9) \\
\hline $\begin{array}{l}\text { ST-segment } \\
\text { elevation }\end{array}$ & $35(41.2)$ & $24(57.1)$ & $17(60.7)$ \\
\hline RB BB & $10(11.8)$ & $4(9.5)$ & $2(7.1)$ \\
\hline LB BB & $14(22.4)$ & 7 (16.7) & $4 .(14.3)$ \\
\hline $\begin{array}{l}\text { ST-segment } \\
\text { depression }\end{array}$ & $1(1.2)$ & $0(0)$ & $0(0)$ \\
\hline
\end{tabular}

transferred to long-term rehabilitation units. The other patients were discharged within 10 days with no neurological deficits.

Prior to their arrival at the hospital, none of the patients had received CPR from bystanders, although the three patients transferred by the EMS had had CPR administered by the paramedics. All patients subsequently received CPR immediately upon arrival at the hospital. Following the administration of in-hospital CPR, 85 patients (39.4\%) returned to spontaneous circulation (RSC). Among this subset, 25 patients (29.4\%) had normal post-RSC ECG findings, while $35(41.2 \%)$ had an ST-segment elevation, 14 (16.5\%) had a left bundle branch block, 10 (11.8\%) had a right bundle branch block and one (1.2\%) had an STsegment depression. Overall, 22 patients (25.9\%) were deemed unfit for an immediate coronary angiography; of these, 17 (77.3\%) experienced a further cardiac arrest and died, while three (13.6\%) and two (9.1\%) patients were diagnosed with strokes and pulmonary emboli, respectively. The remaining 63 patients (74.1\%) were taken for either an immediate or urgent coronary angiography, which revealed significant coronary lesions (i.e. $>70 \%$ luminal stenosis) in 42 patients (66.7\%), of which only 28 (66.7\%) required stenting. Most of the patients who required stenting had an STsegment elevation (60.7\%) [Table 2].

No correlation was found between survival and stenting of the coronary artery, the location of the lesion or the number of vessels involved. However, the survival rate was significantly poorer among patients with triple-vessel disease in comparison to those with double-vessel disease, single-vessel disease or normal coronary arteries $(7.1 \%$ versus $40 \%, 50 \%$ and $45 \%$, respectively; $P=0.05)$. In addition, patients in whom 
Table 3: Factors affecting outcomes among resuscitated* patients presenting following an out-of-hospital cardiac arrest to the Sultan Qaboos University Hospital, Muscat, Oman $(\mathrm{N}=85)$

\begin{tabular}{|c|c|c|c|}
\hline \multirow[t]{2}{*}{ Variable } & \multicolumn{2}{|c|}{ n (\%) } & \multirow{2}{*}{$\begin{array}{c}P \\
\text { value }\end{array}$} \\
\hline & $\begin{array}{c}\text { Survived } \\
(\mathrm{n}=28)\end{array}$ & $\begin{array}{c}\text { Died } \\
(\mathbf{n}=57)\end{array}$ & \\
\hline \multicolumn{4}{|l|}{ CPR } \\
\hline $\begin{array}{l}\text { Median time } \\
\text { before-hand in } \\
\text { minutes (IQR) }\end{array}$ & $10(0-30)$ & $30(20-40)$ & $<0.01$ \\
\hline $\begin{array}{l}\text { Median duration in } \\
\text { minutes (IQR) }\end{array}$ & $12(6-20)$ & $20(15-30)$ & $<0.01$ \\
\hline \multicolumn{4}{|l|}{ Blood investigations } \\
\hline $\begin{array}{l}\text { Mean serum } \\
\text { potassium in } \mathrm{mEq} / \mathrm{L} \\
\pm \mathrm{SD}\end{array}$ & $4.5 \pm 1.1$ & $3.9 \pm 1.7$ & 0.09 \\
\hline $\begin{array}{l}\text { Median ABG pH } \\
\text { (IQR) }\end{array}$ & $7.1(6.9-7.2)$ & $6.9(6.7-7.0)$ & 0.02 \\
\hline $\begin{array}{l}\text { Median serum } \\
\text { creatinine in } \mathrm{mg} / \mathrm{dL} \\
\text { (IQR) }\end{array}$ & $81(67-128)$ & $99(66-170)$ & 0.43 \\
\hline Catheterisation & & & $0.21^{\dagger}$ \\
\hline Yes & $23(37.1)$ & $39(62.9)$ & \\
\hline No & $5(21.7)$ & $18(78.3)$ & \\
\hline Significant disease & & & $0.41^{\dagger}$ \\
\hline Yes & $14(33.3)$ & $28(66.7)$ & \\
\hline No & $9(42.9)$ & $12(57.1)$ & \\
\hline Vessel involved & & & $0.12^{\dagger}$ \\
\hline LAD artery & $10(29.4)$ & $24(70.6)$ & \\
\hline Circumflex artery & $5(23.8)$ & $16(76.2)$ & \\
\hline RCA & $5(22.7)$ & $17(77.3)$ & \\
\hline \multicolumn{3}{|c|}{ Number of vessels involved } & 0.05 \\
\hline 0 & $9(45)$ & $11(55)$ & \\
\hline 1 & $9(50)$ & $9(50)$ & \\
\hline 2 & $4(40)$ & $6(60)$ & \\
\hline 3 & $1(7.1)$ & $13(92.9)$ & \\
\hline \multicolumn{2}{|l|}{ Intracoronary stenting } & & $0.38^{\dagger}$ \\
\hline Yes & $10(35.7)$ & $18(64.3)$ & \\
\hline No & $13(37.1)$ & $22(62.9)$ & \\
\hline IABP & & & 0.02 \\
\hline Yes & $2(12.5)$ & $14(87.5)$ & \\
\hline No & $23(43.4)$ & $30(56.6)$ & \\
\hline TPW & & & 0.16 \\
\hline Yes & $2(16.7)$ & $10(83.3)$ & \\
\hline No & $23(40.4)$ & $34(59.6)$ & \\
\hline
\end{tabular}

$C P R=$ cardiopulmonary resuscitation; $I Q R=$ interquartile range; $S D=$ stand ard deviation; $A B G=$ arterial blood gas; $L A D=$ left anterior descending; $R C A$ = right coronary artery; IABP = intra-aortic balloon pump; TPW = temporary pacing wire. *After returning to spontaneous circulation. ${ }^{+}$Calculated using a Chi-squared test.
Table 4: Outcomes of patients presenting following an out-of-hospital cardiac arrest to the Sultan Qaboos University Hospital, Muscat, Oman, according to initial cardiac rhythm $(\mathrm{N}=216)$

\begin{tabular}{lccc} 
Cardiac rhythm & \multicolumn{3}{c}{$\mathbf{n}(\%)$} \\
& Total & Survived & Died \\
PEA & $54(25)$ & $17(31.5)$ & $37(68.5)$ \\
Asystole & $137(63.4)$ & $2(1.5)$ & $135(98.5)$ \\
VT/VF & $23(10.6)$ & $8(34.8)$ & $15(65.2)$ \\
Heart blockage & $2(0.9)$ & $1(50)$ & $1(50)$ \\
PEA = pulseless electrical activity; $V T$ = ventricular tachycardia; \\
$V F=$ ventricular fibrillation.
\end{tabular}

Table 5: Outcomes of resuscitated* patients presenting following an out-of-hospital cardiac arrest to the Sultan Qaboos University Hospital, Muscat, Oman, according to electrocardiography findings $(\mathrm{N}=85)$

\begin{tabular}{lccc} 
ECG findings & \multicolumn{3}{c}{$\mathbf{n}(\%)$} \\
& Total & Survived & Died \\
Normal & $25(29.4)$ & $5(20)$ & $20(80)$ \\
ST-segment elevation & $35(41.2)$ & $11(31.4)$ & $24(68.6)$ \\
RB BB & $10(11.8)$ & $4(40)$ & $6(60)$ \\
LB BB & $14(16.5)$ & $8(61.5)$ & $6(46.2)$ \\
$\begin{array}{l}\text { ST-segment } \\
\text { depression }\end{array}$ & $1(1.2)$ & $0(0)$ & $1(100)$ \\
\hline
\end{tabular}

$E C G$ = electrocardiography; $R B=$ right bundle; $B B=$ branch block; $L B=$ left bundle.

*After returning to spontaneous circulation.

an intra-aortic balloon pump (IABP) was deployed were significantly less likely to survive (12.5\% versus 43.4\%; $P=0.02$ ). In contrast, survival was significantly greater among cases in which CPR was initiated more rapidly $(P<0.01)$ and for a shorter duration of time $(P<0.01)$ [Table 3]. In terms of their initial cardiac rhythm, survival was lowest among patients with asystole (1.5\%) and highest among those with a heart blockage (50\%) followed by VT/VF (34.8\%) [Table 4]. According to their ECG findings, patients with a left bundle branch block more frequently survived (61.5\%) in contrast to those with normal ECG findings (20\%) or an ST-segment depression (0\%) [Table 5].

\section{Discussion}

Despite reported variations in the international literature, $\mathrm{OHCA}$ is consistently associated with poor survival. ${ }^{2,6,7,14}$ In the USA, more than 300,000 deaths annually are attributed to an OHCA, whilst this accounts for approximately 28,000 deaths per year in the UK. ${ }^{15,16}$ In the current study, the survival rate for patients presenting to SQUH following an OHCA was very low (13\%). Nevertheless, it is likely that this percentage is an overestimation, as it does not include 
patients who were declared DOA. As with other research, the majority of such DOA cases were found at home rather than in a public place. ${ }^{3}$ As this often means that the cardiac arrest was not witnessed, death is more probable due to delays in seeking medical assistance.

In Amsterdam, Waalewijn et al. demonstrated the benefits of bystander CPR in improving outcomes among OHCA patients. ${ }^{7}$ In Western countries such as the UK, USA and Sweden, rates of bystander CPR are relatively high, ranging from $30-50 \%{ }^{15,17,18}$ This high level of bystander participation is primarily due to public education efforts involving mass media campaigns and CPR training programmes. ${ }^{19}$ In the current study, apart from those who were transferred to the hospital by ambulance, none of the patients received bystander CPR or first aid prior to presentation. A previous survey from Saudi Arabia demonstrated a low level of interest in and knowledge of CPR among university students. ${ }^{20}$ Improving health education and conducting awareness campaigns regarding the benefits and methods of performing CPR are recommended to address this issue in the Omani community. Furthermore, ensuring the availability of automated electrical defibrillators in public places should be encouraged as these may be of benefit in certain situations. ${ }^{14,21}$

In Oman, there is a well-established EMS system in place with fully trained and equipped paramedics who can administer CPR if required. ${ }^{22}$ Moreover, most people in Oman live in the governorate of Muscat, a region with excellent EMS coverage. ${ }^{13,22}$ Nevertheless, in the majority of cases in the current study, family members brought collapsed patients directly to the hospital by private car rather than initiating CPR on site or contacting the EMS. Clearly, utilisation of the EMS system is low in Oman, as in other Gulf countries. ${ }^{23}$ Unfortunately, delays in initiating CPR were found to significantly affect survival in the present study. Therefore, reliance on individual family members to bring patients to hospital rather than the EMS system is potentially one of the biggest barriers to improving outcomes of patients with OHCA in the region, as this causes delays in timely medical attention or resuscitation efforts.

In accordance with previous research, patients in the current study who presented with asystole had the worst prognosis. ${ }^{1}$ However, stenting was not found to significantly improve survival; this is in contrast to findings reported by Dumas et al. ${ }^{24}$ Perhaps the reason for this surprising finding was due to the delay in initiating CPR for most patients in the present sample; this would likely affect the overall prognosis, regardless of whether the patients received a stent or not. Similarly, there was no significant difference in survival according to the coronary artery affected, although patients with triple-vessel disease survived less frequently. The use of an IABP was significantly associated with poor survival; however, this could be due to selection bias, as patients who were haemodynamically unstable would have had an IABP inserted.

As per international guidelines, all resuscitated patients at SQUH who have experienced a cardiac arrest undergo coronary angiography, with those who have an ST-segment elevation identified via postresuscitation ECG undergoing immediate coronary angiography. ${ }^{11,12}$ These patients were found to require more stents than any other group of patients in the current study. In contrast, patients without an STsegment elevation receive coronary angiography only after other investigations have been performed, including a blood workup, a computed tomography (CT) scan of the brain and a CT pulmonary angiography to rule out a pulmonary embolism. In the present study, only 28 of the 63 patients who received coronary angiography were found to have a lesion that required stenting. Overall, the neurological outcomes of the patients who survived were relatively good, as there were only three patients with severe residual hypoxic brain injuries. However, it is possible that those with severe brain injuries did not survive to discharge.

This study is subject to several limitations. Due to the retrospective design of the study, missing or erroneous documentation might have compromised the quality of the data collected. The results of blood investigations were not available for the majority of patients, particularly those who could not be resuscitated. Furthermore, neither patients who were declared DOA nor those who had experienced OHCAs but were not resuscitated or brought to the hospital were included in the study. Another limitation was the fact that most patients were brought to the hospital by their relatives or friends; hence, the period of time reported between the cardiac arrest and patient presentation and the subsequent administration of CPR was most likely an approximation. Finally, as this study was based on a single centre experience, the sample size was relatively small and the results may not reflect the true incidence and outcomes of OHCA in Oman.

\section{Conclusion}

Patients presenting to SQUH following an OHCA were found to have a high mortality rate, most likely contributed to by delays in the initiation of CPR efforts. 
Furthermore, the rate of bystander CPR was very low. It is therefore necessary that greater efforts be made to improve public awareness of the benefits of CPR and provide CPR training opportunities to members of the Omani community.

\section{CONFLICT OF INTEREST}

The authors declare no conflicts of interest.

\section{FUNDING}

No funding was received for this study.

\section{References}

1. de Vreede-Swagemakers JJ, Gorgels AP, Dubois-Arbouw WI, van Ree JW, Daemen MJ, Houben LG, et al. Out-of-hospital cardiac arrest in the 1990's: A population-based study in the Maastricht area on incidence, characteristics and survival. J Am Coll Cardiol 1997; 30:1500-5. doi: 10.1016/S0735-1097 (97)00355-0.

2. Roger VL, Go AS, Lloyd-Jones DM, Benjamin EJ, Berry JD, Borden WB, et al. Executive summary: Heart disease and stroke statistics - 2012 update: A report from the American Heart Association. Circulation 2012; 125:188-97. doi: 10.1161/ CIR.0b013e3182456d46.

3. Becker L, Eisenberg M, Fahrenbruch C, Cobb L. Public locations of cardiac arrest: Implications for public access defibrillation. Circulation 1998; 97:2106-9. doi: 10.1161/01.CIR.97.21.2106.

4. Atwood C, Eisenberg MS, Herlitz J, Rea TD. Incidence of EMStreated out-of-hospital cardiac arrest in Europe. Resuscitation 2005; 67:75-80. doi: 10.1016/j.resuscitation.2005.03.021.

5. Hawkes C, Booth S, Ji C, Brace-McDonnell SJ, Whittington A, Mapstone J, et al. Epidemiology and outcomes from outof-hospital cardiac arrests in England. Resuscitation 2017; 110:133-40. doi: 10.1016/j.resuscitation.2016.10.030.

6. Lindner TW, Søreide E, Nilsen OB, Torunn MW, Lossius HM. Good outcome in every fourth resuscitation attempt is achievable: An Utstein template report from the Stavanger region. Resuscitation 2011; 82:1508-13. doi: 10.1016/j.resuscit ation.2011.06.016.

7. Waalewijn RA, Tijssen JG, Koster RW. Bystander initiated actions in out-of-hospital cardiopulmonary resuscitation: Results from the Amsterdam Resuscitation Study (ARRE-SUST). Resuscitation2001; 50:273-9. doi: 10.1016/S0300-9572(01)00354-9.

8. Wissenberg M, Lippert FK, Folke F, Weeke P, Hansen CM, Christensen EF, et al. Association of national initiatives to improve cardiac arrest management with rates of bystander intervention and patient survival after out-of-hospital cardiac arrest. JAMA 2013; 310:1377-84. doi: 10.1001/jama.2013.278483.

9. Hazinski MF, Nolan JP, Billi JE, Böttiger BW, Bossaert L, de Caen AR, et al. Part 1: Executive summary - 2010 international consensus on cardiopulmonary resuscitation and emergency cardiovascular care science with treatment recommendations. Circulation 2010; 122:S250-75. doi: 10.1161/CIRCULATIONA HA.110.970897.

10. Spaulding CM, Joly LM, Rosenberg A, Monchi M, Weber SN, Dhainaut JF, et al. Immediate coronary angiography in survivors of out-of-hospital cardiac arrest. N Engl J Med 1997; 336:1629-33. doi: 10.1056/NEJM199706053362302.
11. Ibanez B, James S, Agewall S, Antunes MJ, Bucciarelli-Ducci C, Bueno $\mathrm{H}$, et al. 2017 ESC guidelines for the management of acute myocardial infarction in patients presenting with STsegment elevation: The task force for the management of acute myocardial infarction in patients presenting with ST-segment elevation of the European Society of Cardiology (ESC). Eur Heart J 2018; 39:119-77. doi: 10.1093/eurheartj/ehx393.

12. Noc M, Fajadet J, Lassen JF, Kala P, MacCarthy P, Olivecrona GK, et al. Invasive coronary treatment strategies for out-of-hospital cardiac arrest: A consensus statement from the European Association for Percutaneous Cardiovascular Interventions (EAPCI)/Stent For Life (SFL) groups. EuroIntervention 2014; 10:31-7. doi: 10.4244/EIJV10I1A7.

13. National Centre for Statistics \& Information. Population: Total population, Muscat, Omani. From: https://data.gov.om/OMPO P2016/population? indicator $=1000140 \&$ region $=1000020$ muscat\&nationality=1000010-omani Accessed: Feb 2018.

14. Murakami Y, Iwami T, Kitamura T, Nishiyama C, Nishiuchi T, Hayashi Y, et al. Outcomes of out-of-hospital cardiac arrest by public location in the public-access defibrillation era. J Am Heart Assoc 2014; 3:e000533. doi: 10.1161/JAHA.113.000533.

15. Nichol G, Thomas E, Callaway CW, Hedges J, Powell JL, Aufderheide TP, et al. Regional variation in out-of-hospital cardiac arrest incidence and outcome. JAMA 2008; 300:1423-31. doi: 10.1001/jama.300.12.1423.

16. Perkins GD, Brace-McDonnell SJ; OHCAO Project Group. The UK Out of Hospital Cardiac Arrest Outcome (OHCAO) project. BMJ Open 2015; 5:e008736. doi: 10.1136/bmjopen-20 15-008736.

17. Perkins GD, Lockey AS, de Belder MA, Moore F, Weissberg P, Gray H. National initiatives to improve outcomes from out-ofhospital cardiac arrest in England. Emerg Med J 2016; 33:448-51. doi: 10.1136/emermed-2015-204847.

18. Hasselqvist-Ax I, Riva G, Herlitz I, Rosenqvist M, Hollenberg I, Nordberg P, et al. Early cardiopulmonary resuscitation in outof-hospital cardiac arrest. N Engl J Med 2015; 372:2307-15. doi: 10.1056/NEJMoa1405796.

19. Abella BS, Aufderheide TP, Eigel B, Hickey RW, Longstreth WT Jr, Nadkarni $\mathrm{V}$, et al. Reducing barriers for implementation of bystander-initiated cardiopulmonary resuscitation: A scientific statement from the American Heart Association for healthcare providers, policymakers, and community leaders regarding the effectiveness of cardiopulmonary resuscitation. Circulation 2008; 117:704-9. doi: 10.1161/CIRCULATIONAHA.107.188486.

20. Al-Mohaissen MA. Knowledge and attitudes towards basic life support among health students at a Saudi women's university. Sultan Qaboos Univ Med J 2017; 17:e59-65. doi: 10.18295/ squmj.2016.17.01.011.

21. Bækgaard JS, Viereck S, Møller TP, Ersbøll AK, Lippert F, Folke F. The effects of public access defibrillation on survival after out-of-hospital cardiac arrest: A systematic review of observational studies. Circulation 2017; 136:954-65. doi: 10.11 61/CIRCULATIONAHA.117.029067.

22. Al-Shaqsi SZ. EMS in the Sultanate of Oman. Resuscitation 2009; 80:740-2. doi: 10.1016/j.resuscitation.2009.04.011.

23. AlHabib KF, Sulaiman K, Al Suwaidi J, Almahmeed W, Alsheikh-Ali AA, Amin H, et al. Patient and system-related delays of emergency medical services use in acute ST-elevation myocardial infarction: Results from the Third Gulf Registry of Acute Coronary Events (Gulf RACE-3Ps). PLoS One 2016; 11:e0147385. doi: 10.1371/journal.pone.0147385.

24. Dumas F, Bougouin W, Geri G, Lamhaut L, Rosencher J, Pène F, et al. Emergency percutaneous coronary intervention in postcardiac arrest patients without ST-segment elevation pattern: Insights from the PROCAT II Registry. JACC Cardiovasc Interv 2016; 9:1011-18. doi: 10.1016/j.jcin.2016.02.001. 